\title{
Parenting Research in Indonesia: What We Have Done So Far
}

\author{
Beatriks Novianti Kiling-Bunga ${ }^{1}$, Kristin Margiani ${ }^{2}$, Indra Yohanes Kiling \\ 1,2Department of Early Childhood Education, Universitas Nusa Cendana \\ ${ }^{3}$ Department of Psychology, Universitas Nusa Cendana
}

Submitted 18 November 2019 Accepted 17 March 2020 Published 22 June 2020

\begin{abstract}
Parenting is one of the most important responsibilities that someone could bear as a parent, probably the most burdensome too. Regardless, several questions are still left unanswered by Indonesian scientists, what are the field of studies related to parenting? What are the problems emanating from the practice of parenting and their solutions? What are the strategic steps one can take as psychology scientist or practitioner to improve parenting in Indonesia? This study examined the application of scoping review to provide responses for aforementioned questions. Just like the way a cartographer map an area in order to advance civilization, a scoping review is meant to enlighten future researchers with the answers on "what has been done?". Five databases were searched in this review, 94 articles were discovered to undergo further rigorous selection, and 16 chosen articles were charted and analyzed accordingly. Finding shows that education, health, and psychology were the field of studies associated with high quality parenting research in Indonesia. Problems in child's development caused by bad parenting attracted most researchers' attention. Solutions provided were unique to each study's context and hard to generalize. Finally, it is suggested that psychologists' involvement in national parenting program is inevitable, and should start from today.
\end{abstract}

Keywords: indonesia; parenting; scoping review

\section{Introduction}

Having children is an inevitable life stage in Indonesian social life post-marriage. Notice when we upload a wedding photo or video in online or social media, there will be a chance of getting "wishing you to have children soon" messages. Sooner or later, similar messages will pop up in the offline world too. Even though having children is considered common in Indonesian society, until today there has yet to be a common understanding on

\footnotetext{
1 Address for correspondence:

beatriks.bunga@staf.undana.ac.id,

${ }^{2}$ kristin.margiani@staf.undana.ac.id,

3indra.kiling@staf.undana.ac.id*
}

ideal parenting practice in Indonesia. Based on a literature review, different cultures influence different parenting practices in Indonesia (Riany, Meredith \& Cuskelly, 2017).

Defined as "the raising of children and all the responsibilities and activities that are involved in it" in the Cambridge Dictionary (2017), parenting is a responsibility attached to parent from the moment their child born until they grow up as an adult. Parenting has influenced every aspects of child development (Morrison, 2009), including physical, emotional, social and cognitive development. In order to support better child development around Indonesia, it is 
crucial to understand how far the progress of parenting research in Indonesia.

Literature review of parenting research have been done in global context and these reviews have identified several important findings. Bradshaw et al. (2019) conducted a scoping review on parenting practices of children with disabilities. This review of 65 studies identified that parenting program that is commonly studied and applied are the Triple-P program in Australia and programs that are designed to fulfill the specific needs of children with disabilities. Another scoping review from Barros and Greffin (2017) explored technology-based parenting interventions that focused on children's health. It identified the focus of parenting interventions in 119 studies were parents self-management, building specific parenting skills and provision of social support.

Up until today, there is no comprehensive review done on parenting research in Indonesia. Understanding the mapping and development of parenting studies would help psychology researchers and practitioners in Indonesia to identify gap of research in parenting topics, and then to strategically plan beneficial study and practice for the future. Considering the significance of parenting study in developing Indonesian society, we have reviewed parenting studies in Indonesia that have been published in good quality journals. We decided to focus on quality publications so that review findings could become a quality milestone and reference for readers in Indonesia and other similar developing countries. Scoping review was chosen as the approach for the review. The objectives of this review were achieved by organizing patterns emerged from reviewed studies. These objectives are: (1) Identifying study fields that examine parenting in Indonesia; (2) Identifying the focus of issues and solutions from parenting studies in Indonesia, and; (3) Discovering strategic steps for psychology researchers and practitioners to develop parenting science and practice in Indonesia.

\section{Discussion}

\section{Scoping Review Stages}

Scoping review method is a set of searching and organizing steps used to broadly map a specific topic or field. This review technique gathers all relevant literatures without restraining design and quality of the study, and then map key information from these literatures to present a comprehensive narrative from the specified topic (Arksey \& O'Malley, 2005). A scoping review that examined the use of scoping review in 344 literatures found that this method is mostly used to explore health-related topics $(74.1 \%)$, meanwhile this method also begins to be applied in several other topics including psychology (Pham et al., 2014).

Scoping review has already been done in Indonesia. Kiling and Bunga (2015) used scoping review to identify studies in psychology field published in journals indexed by PsycINFO database. In addition to mapping literatures in a specific field, scoping review was also used by Kiling-Bunga, Kiling and Keraf (2016) to scope studies in a specific topic about social media in Indonesia that is indexed in three different databases (PsycINFO, PubMed dan Scopus).

Mastering scoping review technique will help Indonesian academics answer question "what has been done in this topic?" that emerges when researching and designing psychological intervention or program. Majority of Indonesian academics have tried to answer that question by doing an unsystematic review. They used 
different keywords randomly to search relevant past literatures, this might result in missing many of relevant studies. Furthermore, unsystematic review has tendency of subjectivity when it comes to selecting references used in the study. Academics often choose to cite studies that improve or support their own study's argument.

Five stages explained by Arksey dan O'Malley (2005) were used in this review: (1) defining the objectives of the review; (2) searching relevant scientific literatures; (3) systematically selecting literatures identified; (4) mapping obtained data; and (5) organizing and presenting the results. Furthermore, to narrow down the review focus, some inclusion and exclusion criteria were applied. The inclusion criteria used were: (1) Article that discussed results from an empirical study; (2) article that studied parenting on human; (3) article that focused on Indonesian people. Next, a study would not be included in the review if they meet the exclusion criteria: (1) parenting study on animal; (2) article contains opinion or literature review; (3) article published in a proceeding; and (4) article published as a book chapter or thesis.

This scoping review only considered studies published in scientific journal, taking into account that publication in scientific journal is the final stage of a study report after revision process. The authors also did not apply limitation on research method utilized, date of publication, or participants contributed in the study. This was done to gather more articles in order to expand the scope of the review. However the authors applied language limitation by only choosing articles in Indonesian and English languages to make the search feasible as these are the languages mainly used by the authors.

\section{Database Literature Search Stages}

Considering that the authors had done scoping review before, this review was done without consulting an academic librarian. The authors suggested that other researchers wanting to conduct a scoping review for the first time to consult to academic librarian or other researchers with experience in doing such review.

PsycINFO, Education Resources Information Center (ERIC), PubMed, Social Services Abstracts and also Scopus were the searched databases. PsycINFO is the database to gather psychology-focused studies, while PubMed is a database for health studies, ERIC for exploring education research, Social Services Abstract for social science literatures, and then Scopus to explore literatures broadly. Web of Science was not searched in this review due to similar characteristics with Scopus as a general database that has no specific field focus. Local Indonesian databases such as SINTA were not involved because at the time research was conducted, SINTA was yet to have an advanced searching feature that could facilitate technical searching stages employed in the scoping review.

The third author (IYK) created a logic grid that contained detail keywords used to search articles in PsycINFO database. This logic grid was then modified so that it can be used in the other databases. Development of the logic grid could be done by considering keywords used in past literatures, or also by looking at logic grids used in similar scoping reviews. Logic grid tables used to search five databases in this review are displayed in Table 1, 2, 3 and 4 to help future reviews in replicating this literature study. Similar logic grid was used in searching ERIC and Social Services because the access that we had in these databases was in a same 
publisher, ProQuest. The EndNote X7 for scoping review results.

Mac application was used to organize

Table 1.

PsycINFO Logic Grid

\begin{tabular}{ll}
\hline \multicolumn{1}{c}{ Parenting } & \multicolumn{1}{c}{ Indonesia } \\
\hline Parenting.ab OR Parenting.ti OR & Indonesia.ab OR Indonesia.ti OR Java.ab OR Java.ti OR \\
Mothering.ab OR Mothering.ti OR & Borneo.ab OR Borneo.ti OR Kalimantan.ab OR Kaliman- \\
Fathering.ab OR Fathering.ti & tan.ti OR Sumatra.ab OR Sumatra.ti OR Celebes.ab OR \\
& Celebes.ti OR Sulawesi.ab OR Sulawesi.ti OR West \\
& Irian.ab OR West Irian.ti OR Indonesian New Guinea.ab \\
& OR Indonesian New Guinea.ti OR Irian Jaya.ab OR Irian \\
& Jaya.ti OR West Papua.ab OR West Papua.ti OR \\
& Madoera.ab OR Madoera.ti OR Madura.ab OR Madura.ti \\
& OR Bali.ab OR Bali.ti OR Nusa Tenggara.ab OR Nusa \\
& Tenggara.ti OR Lesser Sunda Islands.ab OR Lesser Sunda \\
& Islands.ti OR Mollucas.ab OR Mollucas.ti OR Maluku.ab \\
& OR Maluku.ti \\
\hline
\end{tabular}

Table 2.

PubMed Logic Grid

\begin{tabular}{lll}
\hline \multicolumn{1}{c}{ Parenting } & \multicolumn{1}{c}{ Indonesia } \\
\hline Parenting[tiab] OR Mothering[tiab] & Indonesia[tiab] OR Java[tiab] OR Borneo[tiab] OR \\
OR Fathering [tiab] & Kalimantan[tiab] OR Sumatra[tiab] OR Celebes[tiab] OR \\
& Sulawesi[tiab] OR West Irian[tiab] OR Indonesian New \\
& Guinea[tiab] OR Irian Jaya[tiab] OR West Papua[tiab] OR \\
& Madoera[tiab] OR Madura[tiab] OR Bali[tiab] OR Nusa \\
& Tenggara[tiab] OR Lesser Sunda Islands[tiab] OR \\
& Mollucas[tiab] OR Maluku[tiab] \\
\hline
\end{tabular}

Table 3.

ERIC dan Social Services Abstract Logic Grid

\begin{tabular}{ll}
\hline \multicolumn{1}{c}{ Parenting } & \multicolumn{2}{c}{ Indonesia } \\
\hline ALL(Parenting) OR & ALL(Indonesia) OR ALL(Java) OR ALL(Borneo) OR \\
ALL(Mothering) OR & ALL(Kalimantan) OR ALL(Sumatra) OR ALL(Celebes) \\
ALL(Fathering) & OR ALL(Sulawesi) OR ALL(“West Irian”) OR ALL \\
& ("Indonesian New Guinea”) OR ALL(“Irian Jaya”) OR \\
& ALL(“West Papua”) OR ALL(Madoera) OR ALL(Madura) \\
& OR ALL(Bali) OR ALL(“Nusa Tenggara”) OR \\
& ALL(“Lesser Sunda Islands") OR ALL(Mollucas) OR \\
& ALL(Maluku) \\
\hline
\end{tabular}


Table 4.

Scopus Logic Grid

\begin{tabular}{ll}
\hline \multicolumn{1}{c}{ Parenting } & \multicolumn{1}{c}{ Indonesia } \\
\hline TITLE-ABS-KEY (Parenting) OR & TITLE-ABS-KEY (Indonesia) OR TITLE-ABS-KEY (Java) \\
TITLE-ABS-KEY (Mothering) OR & OR TITLE-ABS-KEY (Borneo) OR TITLE-ABS-KEY \\
TITLE-ABS-KEY (Fathering) & (Kalimantan) OR TITLE-ABS-KEY (Sumatra) OR TITLE- \\
& ABS-KEY (Celebes) OR TITLE-ABS-KEY (Sulawesi) OR \\
& TITLE-ABS-KEY ("West Irian”) OR TITLE-ABS-KEY \\
& ("Indonesian New Guinea”) OR TITLE-ABS-KEY (“Irian \\
& Jaya”) OR TITLE-ABS-KEY (“West Papua”) OR TITLE- \\
& ABS-KEY (Madoera) OR TITLE-ABS-KEY (Madura) OR \\
& TITLE-ABS-KEY (Bali) OR TITLE-ABS-KEY (“Nusa \\
& Tenggara”) OR TITLE-ABS-KEY (“Lesser Sunda Islands”) \\
& OR TITLE-ABS-KEY (Mollucas) OR TITLE-ABS-KEY \\
& (Maluku) \\
\hline
\end{tabular}

The first and third authors separately selecting titles and abstracts identified from the search, then respectively categorizing the articles, whether they are considered as relevant or irrelevant articles, according to inclusion and exclusion criteria decided. Next, relevant articles were then read in full-text in order to select fitting articles to be included in the scoping review. Scientific articles that cannot be accessed by the authors were selected by their abstracts only. The second author provided considerations whenever there was a dispute between the first and third author in the selection process.

To map the data, the authors used format explained by Levac et al. (2010). This mapping guide was used to extract data from the included articles in this scoping review. Data extracted varied from the researchers to the main issues and solutions focused in the study.

\section{Quality Literatures on Parenting in Indonesia}

Total of 94 articles were identified from the search on five databases. After doing selection based on titles and abstracts of the literatures, total of 71 articles were excluded from the review based on inclusion and exclusion criterias and also article duplication (same article found several times in different databases).

The authors found that many studies were irrelevant in the database search due to the articles were not published in journals, but in book chapters and dissertation or thesis. Next, seven literatures were excluded in the full-text selection due to meeting exclusion criteria such as parenting in animal, written in Mandarin, and article could not be accessed due to the authors' limited pass. Sixteen articles passed the final full-text selection and included in the scoping review.

From 16 articles, total of 13 articles were published in between 2013 to 2017. Only three articles published before 2013. Further, there were four articles that studied Indonesia and other countries simultaneously (Mindell, Sadeh, Kohyama, \& How, 2010; Ramamurthy et al., 2012; Sumargi, Sofronoff, \& Morawska, 2015; Fulu et al., 2017), other 12 articles focused solely in Indonesian context. Table 5 provides detailed information on 16 articles included in the review. 
KILING-BUNGA, et al

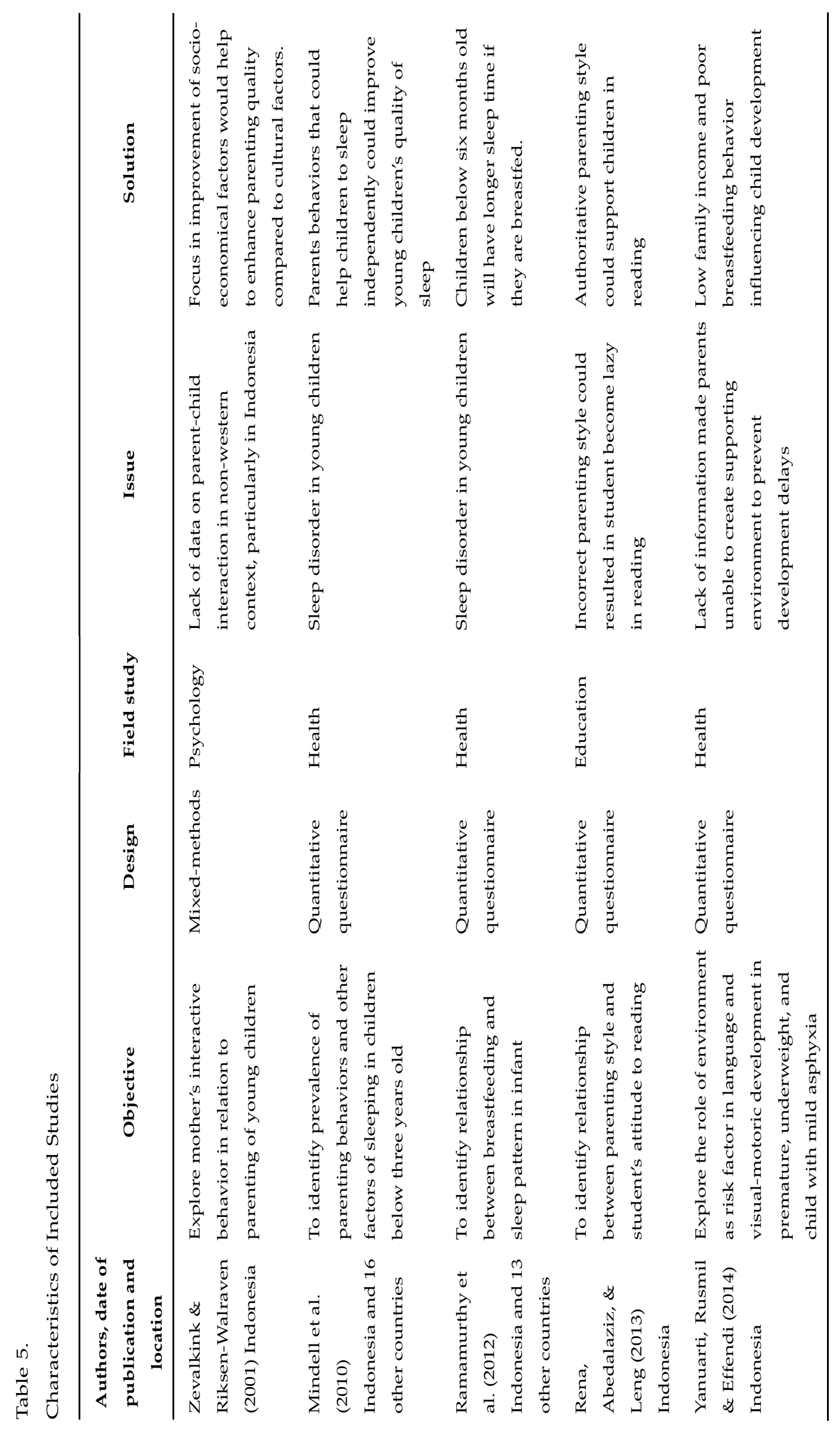


PROGRESS OF PARENTING RESEARCH IN INDONESIA

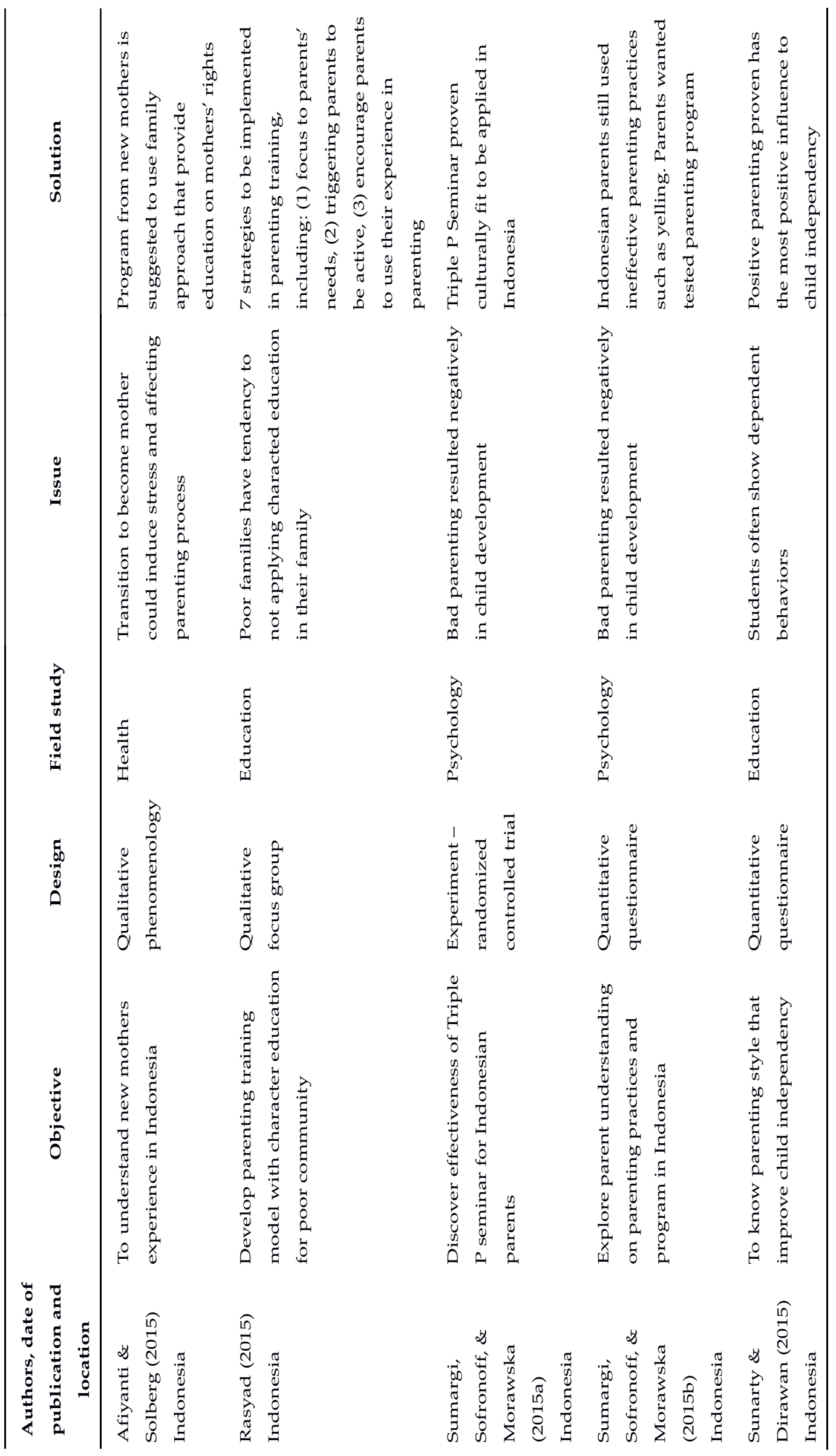




\section{Parenting Research Field in Indonesia}

Data extraction showed that the distribution of research fields studying parenting in Indonesia are only a few yet equally distributed. Only three study field identified in this review: education with six studies, and psychology and health with five studies each. Parenting as defined by Indonesian Psychological Association (HIMPSI) is education in family, reflecting the strong attachment of parenting with education field, particularly education outside of school. These six education-focused parenting studies explored relationships of parenting with various variables such as reading behavior, poverty, dependent behavior, fighting, aggresiveness, and health promotion.

Even though these six studies were extracted from international databases, the authors found that these articles were not well-written, especially in English writing. For example, Sunarsih et al. (2016) study was hard to digest from the title up to references. Other education-focused studies were presented with poor transitions between and within paragraphs, making the main point of each paragraph hard to be identified.

Important message from this finding is that even recognized international databases have not been able to fully filter out some articles that are inconsistent in their publications (sometimes publishing well-edited articles, and sometimes do not). Therefore, setting Scopus-indexed articles (or Web of Science) as one of the highest achievement in Indonesian research publication system could be regarded as an unwise regulation. If explored further, the well regarded impact factor value in scientific journal is currently being set aside by the presence of open-access journal.

An emerging question from that reflection is that, until when will we send our best products (scientific reports) to foreign journals? We as Indonesian academics have been incessant in calling for our own Nusantara-focused (archipelago) study field, yet we are still half-hearted in building our "best home" to produce and accommodate domestic research field.

Next, the authors found that healthrelated parenting studies are better in the writing quality. This however might be related to the fact that three out of five studies were comparison studies of Indonesian context with other countries, which also put foreigners as first author of these studies. This particular pattern was also identified by a past scoping review by Kiling and Bunga (2015) that explored psychology publications indexed by PsycINFO. The dominant contribution (or rather, lead) by foreigners might be needed in order to build the confidence of Indonesian academics before independently conducting international quality research. Surely to support our academics' independency, plenty resources have to be provided by policy makers to fund crucial services like article proofreading and editing, especially for domestic scientific journals.

For psychological-related parenting studies, it was found that four out of five studies were parts of dissertations for $\mathrm{PhD}$ degree. The first author of these four articles were doctoral students in Australian universities. The main question that arises is: when they finished their doctoral program and return to Indonesia, will they be able to independently produce a high quality, internationally recognized studies? 
Compared to health- and educationfocused parenting studies, psychological parenting studies more frequently applied quantitative design (four studies) compared to other methods. This point reflects the trend of Western psychology research that is becoming dominantly quantitative with each passing day. What about the trend of Indonesian psychology studies?

\section{Issues and Solutions of Parenting in Indonesia}

Half (eight) of the studies in this review put focus in issues related to negative impact resulted from poor parenting styles or practices. These studies mentioned that poor parenting practices are harsh disciplinary methods with tendencies to use physical aggression such as punching and pinching. Further, poor social support from parents, comparing own children to other children, poor figure example, and overprotectiveness in child rearing were considered as poor parenting practices by studies in this scoping review. Inappropriate parenting practices are indeed lately have been highlighted by many stakeholders such as child rights activists and mass media. Coupled with the fact that its impact is invisible to parents and children, and poor resources to accommodate positive parenting practices, parenting pressure for parents are not to be underestimated.

Let us consider the phenomenon of gadget consumption on children. Experts from American Academy of Pediatrics (AAP, 2016) suggested that screen time for children needs to be strictly limited. Children aged two to five years old for example, are suggested to only use gadget or other electronic medias for one hour per day. Mass media also often put more pressure by focusing on the examples from Bill Gates and the late Steve Jobs, who themselves limited their children's gadget consumption.

The reality in Indonesia, it is generally difficult to limit gadget consumption on children. Parents more often than not have to work using their gadgets, limited entertainment options in home, limited outdoor play areas, peers who actively use gadgets, are some influencing factors that made suggestion from AAP seems impossible to apply. Just from the responsibility of limiting their children's gadget consumption, parents are already experiencing great pressure in parenting practice.

The authors argue that parents have to admit that total control on their children's development is not something that can be achieved or have to be pursued. Parents are suggested to identify their children's developmental stage needs, and adapt to different demands emerged in every developmental stage. An important fact to mention is that there was not a single study in this review that explored the relation between parenting and gadget or internet consumption behavior. This gap presents a good opportunity to be considered by parenting researchers in the future.

Just like mentioned above, different developmental stages require different solutions too. This also reflects in the variety of solutions that were brought up by 16 studies in this scoping review. In detail, parenting quality in Indonesia will be improved with adequate family economy capacity, supportive social environment, good breastfeeding practice, family-based parenting education training, adaptation of Triple $\mathrm{P}$ seminar from Australia, book reading program, parents group discussion, and application of appropriate parenting style in specific context. 
Even though universal parenting concept has long been explored and obtained scientific evidence support (McEvoy et al., 2005), according to this review, solutions for parenting issues are contextual based and difficult to be generalized. This resulted in formulation of parenting intervention/program would always require in depth contextual study.

\section{Parenting Strategic Stages}

A pattern that emerge from 16 studies in this scoping review is the dominant role of psychology in providing scientific information in the topic of child development. Considering the low quantity of good parenting studies in Indonesia, the authors see that it is important that psychology scientists to continuously conduct parenting-focused research and its relation with child development. A strong focus in one specific topic will build a strong and high quality collection of evidence, which will be able to provide various alternative solutions to crucial and contextual parenting issues and strengthening the application effect of these evidences.

Practically, just like how psychologists in Indonesia have been integrated in Puskesmas (public health center), the authors consider that now is the time for psychologists to be affiliated with government agencies that closely related to parenting practices such as National Population and Family Planning Board (BKKBN). Ideally, parenting education by psychologists could be obtained in Posyandu (integrated service post) and/or in bina keluarga balita (assistance for family with toddler). Such initiative could only emerge when policy makers treat productive and non-productive community groups equally. Because when will parents be able to provide love and care to their children when they are demanded to "work, work, work" all the time?

\section{Conclusion}

Parenting studies in Indonesia have developed rapidly until today, lead by academics from education, psychology and health science fields. This means that other related study fields such as anthrophology, sociology, theology and economy still have a large opportunity to contribute in developing Indonesian parenting science. Psychology scientists can initiate this by conducting cross field studies that involve academics from various fields mentioned previously. Consideration of indigenous child rearing values and practices (e.g. asah, asih asuh) is a necessity in developing authentic and communitybased evidence. Participatory-based research approach could be used to increase community ownership of the studies, therefore improving its application and sustainability.

Poor parenting still becomes a main concern for academics. The rapid development of technology and civilization hugely influence parenting dynamics from time to time. Conflicts between traditional and contemporary parenting ideals tend to disorient parents in Indonesia as they struggle to adjust. Good parenting practices today can become poor practices tomorrow. Psychology scientists need to adapt and supply appropriate parenting evidence to Indonesian parents so that poor parenting issues could be minimalized following the trend changes and dynamics of global parenting community. Cooperation between sectors becomes more urgent in order to facilitate parenting programs. The question is, when will the cooperation improve if policy makers are 
still segmented in regulating budget and executing programs?

\section{References}

Afiyanti, Y., \& Solberg, S. M. (2015). "It is my destiny as a woman": On becoming a new mother in Indonesia. Journal of Transcultural Nursing, 26(5), 491-498. doi:

\section{$10.1177 / 1043659614526243$}

American Academy of Pediatrics (2016). American Academy of Pediatrics announces new recommendations for children's media use. Retrieved 11 September, 2017 from https://www.aap.org/en-us/about-theaap/aap-press-room/pages/americanacademy-of-pediatrics-announces

Arksey, H., \& O'Malley, L. (2005). Scoping studies: Towards a methodological framework. International Journal of Social Research Methodology, 8(1), 19-32.

Barros, L., \& Greffin, K. (2017). Supporting health-related parenting: A scoping review of programs assisted by the internet and related technologies. Estudos de Psicologia (Campinas), 34(3), 331-344. doi: 10.1590/198202752017000300002

Bradshaw, S., Bem, D., Shaw, K., Chiswell, C., Salama, M., Bassett, E., ... \& Cummins, C. (2019). Improving health, wellbeing and parenting skills in parents of children with special health care needs and medical complexity A scoping review. BMC Pediatrics, 19, 301. doi: $\underline{10.1186 / s 12887-019-1648-7}$

Cambridge Dictionary (2017). Meaning of "parenting" in the English Dictionary. Retrieved 10 September, 2017 from http://dictionary.cambridge.org/dictio nary/english/parenting

Fulu, E., Miedema, S., Roselli, T., McCook, S., Chan, K. L., Haardorfer, R., \&
Jewkes, R. (2017). Pathways between childhood trauma, intimate partner violence, and harsh parenting: findings from the UN Multi-country Study on Men and Violence in Asia and the Pacific. Lancet Global Health, 5(5), e512-e522. doi: 10.1016/S2214109X(17)30103-1

Kiling, I. Y., \& Bunga, B. N. (2015). Identify Indonesia psychology publications in PsycINFO database: A scoping review. Anima, Indonesian Psychological Journal, 30(3), 139-147.

Kiling-Bunga, B. N., Kiling, I. Y., \& Keraf, M. K. P. A. (2016). Meneropong penelitian media sosial di Indonesia. In J. S. A. Utama, J. Abraham, T. Susana, I. N. Alfian, \& A. Supratiknya (Eds.), Psikologi dan Teknologi Informasi (Seri Sumbangan Pemikiran Psikologi Untuk Bangsa 2) (pp. 211-225). Jakarta: Himpunan Psikologi Indonesia.

Levac, D., Colquhoun, H., \& O'Brien, K. (2010). Scoping studies: Advancing the methodology. Implementation Science, 5(1), 1-9.

McEvoy, M., Lee, C., O'Neill, A., Groisman, A., Roberts-Butelman, K., Dinghra, K., \& Porder, K. (2005). Are there universal parenting concepts among culturally diverse families in an inner-city pediatric clinic? Journal of Pediatric Health Care, 19(3), 142-150. doi: 10.1016/j.pedhc.2004.10.007

Mindell, J. A., Sadeh, A., Kohyama, J., \& How, T. H. (2010). Parental behaviors and sleep outcomes in infants and toddlers: A cross-cultural comparison. Sleep Medicine, 11(4), 393-399. doi: 10.1016/j.sleep.2009.11.011

Morrison, F. J. (2009). Parenting and academic development. Merrill-Palmer Quarterly, 55, 361-372.

Nurhaeni, H., Dinarti, D., \& Priharti, D. 
(2016). The family parenting influenced adolescent brawls behavior. International Journal of Evaluation and Research in Education, 5(2), 126-134.

Pham, M. T., Rajic, A., Greig, J. D., Sargeant, A. M., Papadopoulos, A., \& McEwen, S. A. (2014). A scoping review of scoping reviews: Advancing the approach and enhancing the consistency. Research Synthesis Methods, 5, 371-385.

Purwati, \& Japar, M. (2016). The parents' parenting patterns, education, jobs, and assistance to their children in watching television, and children's aggressive behavior. International Education Studies, 9(2), 89-94.

Ramamurthy, M. B., Sekartini, R., Ruangdaraganon, N., Huynh, D. H., Sadeh, A., \& Mindell, J. A. (2012). Effect of current breastfeeding on sleep patterns in infants from AsiaPacific region. Journal of Paediatrics and Child Health, 48(8), 669-674. doi: 10.1111/j.1440-1754.2012.02453.x

Rasyad, A. (2015). Developing a parenting training model of character education for young learners from poor families by using transformative learning approach. International Education Studies, 8(8), 50-56.

Rena, S., Abedalaziz, N., \& Leng, C. H. (2013). The relationship between parenting styles and students' attitude toward leisure time reading. Malaysian Online Journal of Educational Sciences, 1(2), 37-54.

Riany, Y. E., Cuskelly, M., \& Meredith, P. (2016). Cultural beliefs about autism in Indonesia. International Journal of Disability, Development and Education, 63(6), 623-640.
Riany, Y. E., Cuskelly, M., \& Meredith, P. (2017). Parenting style and parentchild relationship: A comparative study of Indonesian parents of children with and without autism spectrum disorder (ASD). Journal of Child and Family Studies, 26, 3559-3571. doi: 10.1007/s10826-017-0840-3

Riany, Y. E., Meredith, P., \& Cuskelly, M. (2017). Understanding the influence of traditional cultural values on Indonesian parenting. Marriage $\mathcal{E}$ Family Review, 53(3), 207-226. doi: 10.1080/01494929.2016.1157561

Sumargi, A., Sofronoff, K., \& Morawska, A. (2015a). A randomized-controlled trial of the Triple P-positive parenting program seminar series with Indonesian parents. Child Psychiatry $\mathcal{E}$ Human Development, 46(5), 749-761. doi: $10.1007 / \mathrm{s} 10578-014-0517-8$

Sumargi, A., Sofronoff, K., \& Morawska, A. (2015b). Understanding parenting practices and parents' views of parenting programs: A survey among Indonesian parents residing in Indonesia and Australia. Journal of Child and Family Studies, 24(1), 141-160. doi: $10.1007 / \mathrm{s} 10826-013-9821-3$

Sunarsih, T., Murti, B., Anantanyu, S., \& Wijaya, M. (2016). Path analysis: Health promotion information access of parent caretaking pattern through parenting education. International Journal of Evaluation and Research in Education, 5(1), 69-75.

Sunarty, K., \& Dirawan, G. D. (2015). Development parenting model to increase the independence of children. International Education Studies, 8(10), 107-113.

Yanuarti, H. P., Rusmil, K., \& Effendi, S. H. (2014). Environment as a risk factor in delayed development in premature, 
low-birthweight and mild asphyxia children. Pediatrics International, 56(5), 720-725. doi: $10.1111 /$ ped.12333

Zevalkink, J., \& Riksen-Walraven, J. M. (2001). Parenting in Indonesia: Inter- and intracultural differences in mothers' interactions with their young children. International Journal of Behavioral Development, 25(2), 167-175. doi: $\quad \underline{10.1080 / 01650250042000113}$ 